\title{
Changes in Tourism Destination Image of Guangzhou
}

\author{
Siying Yang ${ }^{\circledR}$, Mu Zhang \\ Shenzhen Tourism College, Jinan University, Shenzhen, China \\ Email: yangsiying_silvia@163.com
}

How to cite this paper: Yang, S. Y., \& Zhang, M. (2020). Changes in Tourism Destination Image of Guangzhou. Journal of Service Science and Management, 13, 594-616.

https://doi.org/10.4236/jssm.2020.133038

Received: May 29, 2020

Accepted: June 26, 2020

Published: June 29, 2020

Copyright $\odot 2020$ by author(s) and Scientific Research Publishing Inc. This work is licensed under the Creative Commons Attribution International License (CC BY 4.0).

http://creativecommons.org/licenses/by/4.0/

\begin{abstract}
This study explored the changes in tourism destination image of Guangzhou through the most popular travel notes collected from Mangfengwo between 2010 and 2019. Tourist Gaze Theory and Symbolic Interaction Theory were applied to the article in order to construct a model of Organic Image and Compound Image, explaining that compound image of previous tourists will make an influence on organic image of potential tourists. We combined content analysis method and cluster analysis method, using NVivo to identify the characters of spaces, emotions and experiences shown in the titles of travel notes. It is found that 1) Attractions in Guangzhou are abundant but the distribution is scattered, and the homogeneity of similar category is high, which can easily lead to the outflow of tourists to the surrounding cities; 2) Tourists have strong perception of the history and local characteristics of Guangzhou, but lack of the perception of modernization; 3) The culture of food has a great importance in shaping and promoting city image of Guangzhou; 4) Parent-child travel can be used as the focus of propaganda. The titles of travel notes are the first factor when attracting readers, which can well reflect their interests and expected impression. Therefore, we suggest that destination marketing organizations should: 1) strengthen the construction of its own tourism resources, differentiate the creation of similar tourism spots and introduce modern technology to enrich the experience of tourists; 2) pay attention to guiding the creation of UGC as the title of travel notes is the first element that comes into tourists' sight and can reflect their interest as well as expected impressions in Guangzhou.
\end{abstract}

\section{Keywords}

UGC, Image Perception, Image Changes, Tourist Gaze Theory, Symbolic Interaction Theory

\section{Introduction}

With the continuous development of new media applications, the empowerment 
of new media has brought more voice to the public, and in the field of tourism, tourists are free to share and express their opinions in a diverse way. At the same time, with the change of idea of traveling, people are no longer limited to visiting scenic, but more to explore destinations from a "localize" way. As a result, tourists' cognitive of destination image no longer rely solely on traditional destination marketing organizations (DMOs), but more depend on User-generated content(UGC), the main productivity of tourism virtual community and travel-related "we media".

Compared with the propaganda from traditional as well as authoritative government or official website organization, UGC is richer and more vivid in content, involving a wider range of tourism images, and more accurately hitting the tourists' pain spots. UGC content covers text, images, video and other forms, in which the infinite nature of text provides a larger imagination space for tourists, easy to arouse tourists' interest in traveling, thus producing a guiding role for potential tourists. In the era of the information explosion, people's choice of article first depends on the title of it, and the current study of the text title is rare. So we select Guangzhou, an important super city in the south of China, as the research object, with the data sources of online travel notes from the well-known tourism community "Mafengwo". We intend to explore the change of urban image representation from the time variation perspective.

In the new media background, "wine is not afraid of the deep alley" theory fails. We are going to find out the solution for DOMs to grasping the preferences of tourists exposed by the UGC in the "de-centralized" new media era (Huang, 2014) and building as well as promoting an attractive image of Guangzhou city.

\section{Literature Review}

In the second half of the 20th century, it's proposed that the destination image is a subjective impression of a non-residential place. With the development of the information age at the end of the 20th century, Fakeye \& Crompton (1991) argued that subjective construction should be based on a large flow of information, while further came up with two information channels, indirectly linked to tourism and directly linked. Domestic scholars, however, continued this part of the study by suggesting that information sources were divided into media (indirect) and actual experiences (direct), so that the destination image was considered as the sum of the perceptions of tourists and potential tourists (Xie \& Huang, 2002; Deng, 2002). The study of destination image did not only seek for a clear definition, but rather required an exploration of the impact made by destination image. At the same time, the tourist inclination was inherently limited by the perception of destination image of tourists and potential travellers, thus researches on destination image could help to better analyse (potential) travellers' motivation to travel and its related factors (Guo, 2003). Among them, the tourist's perception of destination image was divided into three types, original image, induced image and composite image. The original image referred to Primary image refers to the destination image perception formed from the individual through information 
sources, such as the non-commercial marketing mass communication, which was endogenous. In contrast, an induced image was consciously promoted by DMOs, and a composite image was a tourist's perception after an actual trip.

In order to better explore tourists' perception of destination image, a large number of scholars had explored destination image from different perspectives (Enright \& Newton, 2004). The measurement dimension covered five types, including points (Alhemoud \& Armstrong, 1996; Baloglu \& Brinberg, 1997; Qu \& Liang, 2017), lines (Liu, 2014), space (Jiao \& Fang, 2010; Wang et al., 2014), time (Gallarza et al., 2002) and temporal union (Huang et al., 2020). Among them, domestic and foreign scholars' analysis based on the temporal dimension was still stuck in the repetitive study of static images, lacking the dynamic comparison of images. The measurement perspectives also varied: Liu et al. (2009) took the tourist perspective and identified the measurement perspective as the destination community and the tourist group; with the flourishing of new media, Feng (2011) used blogging as a vehicle to expand the study of groups to a comparative study between groups. Guo (2012) took the perspective of the destination management organization. In addition, specific measures of destination image had also undergone a change. Pike (2002) found that the initial research focused on qualitative methods of analysis, with a few quantitative analyses preferred t-test, mean value analysis and so on; the research content had taken a variety of forms and involved texts, photos and other analyses, but photos analysis was in small numbers. Nowadays, with the diversification of information forms and the rapid development of technology, the content form of destination image research expanded to dynamic information such as video (Wu \& Shen, 2018). Research methods also spanned multiple disciplines (Deng et al., 2019), but interdisciplinary research focused on the presentation of technological development, such as the application of convolutional neural network models (Yan \& Zheng, 2020), and the research focus of destination image itself was weakened.

In recent years, a growing number of scholars' research on destination image relied on mass media, and a wealth of research confirmed that changes in tourists' perceptions of destination image were influenced by mass media indoctrinating information (Wang et al., 2015). Among them, online comments could influence tourists' willingness to travel (Shin et al., 2019). However, Zang \& Huang (2007) had suggested that there were significant differences in the destination image created by different websites, influenced by the target audience, leading to confusion in the destination image. Stepchenkova and Zhan (2013) divided destination image shaping into UGC and DMOs. Distinguishing them from the official nature of DMOs, UGC was originated from the Internet, which was unofficial and created by users. Meanwhile, the team measured the differences between these two in shaping the destination image, and draw to a conclusion that DMOs focused on comprehensive expressions including natural beauty, architecture, customs and traditions, and art, while UGC reflected tourists' preferences for certain topics of the destination. In order to attract more tourists, 
DMOs also tried to "mythologize" places (Pi, 2018). With the increasing power of tourist discourse in recent years, UGC had a greater impact on tourists' perceived destination image compared to information offered by DMOs (Álvarez et al., 2020).

Currently, UGC research mostly has focused on textual content analysis. Taking TripAdvisor, a foreign community, as an example, Wang Kun and his collaborators (2014) investigated the international attention of Chinese tourism based on spatial perspective, and Feng \& Hunagpu (2017) analyzed the image of the Forbidden City from the perspective of communication science. Taking domestic communities such as Ctrip as an example, Liu (2019) also conducted image analysis of specific cities from the perspective of communication, combining tourism gaze theory; Lu \& Liao (2019) added the perspective of sentiment analysis, and Zhu et al. (2019) studied from the perspective of temporal and spatial mobility. Different research perspectives blossomed.

In terms of destination selection, some studies have used Guangzhou Shangxiajiu Street as an example to explore the image of specific areas of the city from the perspective of DMOs (Dai \& Chen, 2010); Zhao et al. (2015) analyzed the urban image through pictures from the perspective of architecture based on Guangdong Province. For Guangzhou city as a whole, Cai \& Lai (2007) explored its image from food culture through questionnaire survey; Liao (2007) used questionnaire study to derive the horizontal difference of Guangzhou tourism image among tourists; Zhu \& Lu (2016) analyzed Guangzhou city image from business tourists, a single tourists group, through text; Qu and Liang (2017) and Liang (2018) investigated Guangzhou overall and partial image through text analysis method, respectively.

In summary, using the textual analysis method, there is still a research gap in the analysis of the temporal development of the original image of Guangzhou city from the perspective of the domestic tourists.

\section{Theories, Methods and Research Design}

\subsection{Theories and Model}

\subsubsection{Tourism Gaze and Symbolic Interaction}

In 1992, the British sociologist Urry proposed the "tourist gaze" theory, which argued that tourism was the process of collecting symbols (Urry, 1992). Tourist gaze was the production and consumption of symbols of specific attractions' meanings, and the production of these symbols was constructed and regulated by some experts and the mass media as a socialized perception (Liu, 2007). According to Zhou Xian, tourism gaze could be divided into pre-tourism, mid-tourism and post-tourism gaze by production stage. In the pre-tourism stage, the tourist autonomously searched for information related to the destination and was influenced by a combination of original and projected images to form an anticipatory perception. Through the actual trip, the tourist corrected the anticipatory image during the trip and formed a perception of the composite image after the 
trip, according to which some tourists created tourism experiences and materialize the act of tourist gaze.

The American scholar Mead proposed the "symbolic interaction theory", which assumed that people interacted with and influenced each other through the transmission of symbols and meaning. Meaning transmission presupposed that there was a shared space of meaning between the two parties, which meant that a common and largely similar life experience and cultural context of the symbolic meanings of the language, text and so on were used in the transmission. However, due to the diversity of social activities, the space of meaning for each social member could not fully overlap, so the function of meaning transmission was to expand the space of overlap (Guo, 2011).

With gradually entering the web3.0 era, the media and platforms continue to expand, people's communication frequency increases, and the overlap space is increasingly extended. As the power of public discourse increases, tourists also rely more and more on the results of the "gaze" of the previous tourists, and the creation after the gaze of the previous tourists also expects to receive the interaction and recognition from others. While both sides exchange the construction and deconstruction of symbols in the "social interaction", continuously expanding the space of common meaning, the "post-gaze" of the actual travelers and the "pre-gaze" of the potential tourists are unified on this basis.

\subsubsection{Model Construction}

According to semiotics, symbols are common to all members in society and can convey the deeper connotations of the tourist's perception of Guangzhou. Saussure suggested that symbols were composed of signified and signifier. "Signified" was the content of the symbol and "signifier" was the form of the symbol. In conjunction with previous researches, this paper divides "Signifier" into three factors: spatial, emotional and behavioral. The online travel notes are the composite images generated after the actual travel of tourists, and the original image perceptions of potential tourists will be constructed by the above three perspectives in the process of mass communication (shown in Figure 1).

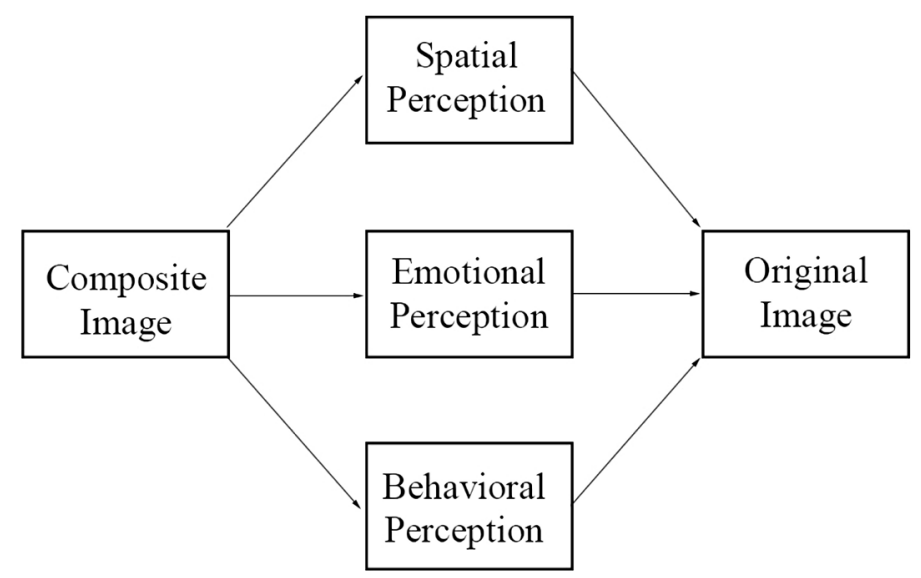

Figure 1. Deconstruction of image. 


\subsection{Research Methodology}

In this paper, content analysis and clustering analysis are used with the help of NVivo 11 tool.

This article selects, classifies and codes the titles of online travel notes, and summarizes the frequency and changes of image words and charts using NVivo 11 , so as to obtain the changes of tourists' perception of the destination image. Since the same data may have different functions in perception, it will be coded multiple times during the coding process. Therefore, this paper will summarize which image elements are most likely to co-occur through the clustering analysis to gain insight into the attractiveness of the destination image to tourists.

\subsection{Data Sources and Screening}

With the increasing pan-socialization of communication resources, people are able to freely choose media platforms to share their travel experiences. However, "we media" generally covers a wide range of topics, in which tourism does not account for a high percentage, and the contents users share are fragmented. Considering the convenience of collection and the quality of textual content, this paper collects data from Mafengwo, a professional travel website. Mafengwo is a leading travel platform in China, mainly targeting domestic travelers, and its UGC covers the whole country and even the world. As is shown in Figure 2, the preliminary survey found that the website has 25,400 articles under the "Guangzhou" module, with the earliest online travel notes dating back to 2006 and the latest ones ending in 2020, meeting the needs of the time, target group and sample source of the research.

Due to the large amount of data on which the website possesses, non-probabilistic sampling is chosen, which has the advantage of drawing exploratory conclusions with less time and effort cost, but also with sampling errors. To minimize measurement errors, the sampling steps in this paper are as follows.

First, widely collecting data. Select Guangzhou as the destination, sort the travel notes by publication time, set the standard of reads and recommendations as the filter conditions. In order to ensure the sample size, considering the development of the website's audience size, using 2014 as the dividing line, the reading volume of the travel notes between 2010 and 2014 was set at more than 1000, with the recommended volume is more than 5; the reading volume of the travel notes between 2014 and 2020 was set at more than 2000, with the recommended volume is more than 10 . The results turned out to be 3445 articles.

Second, sift through the data. On the basis of big data crawling technology, the data collected was ranked based on the number of reads as the primary criterion, in which the top 100 most popular travel notes per year were sampled between 2012 and 2019.

Finally, finalize the data. The quality of the travel notes was further tested by excluding non-significant headings, such as those with the destination as the 


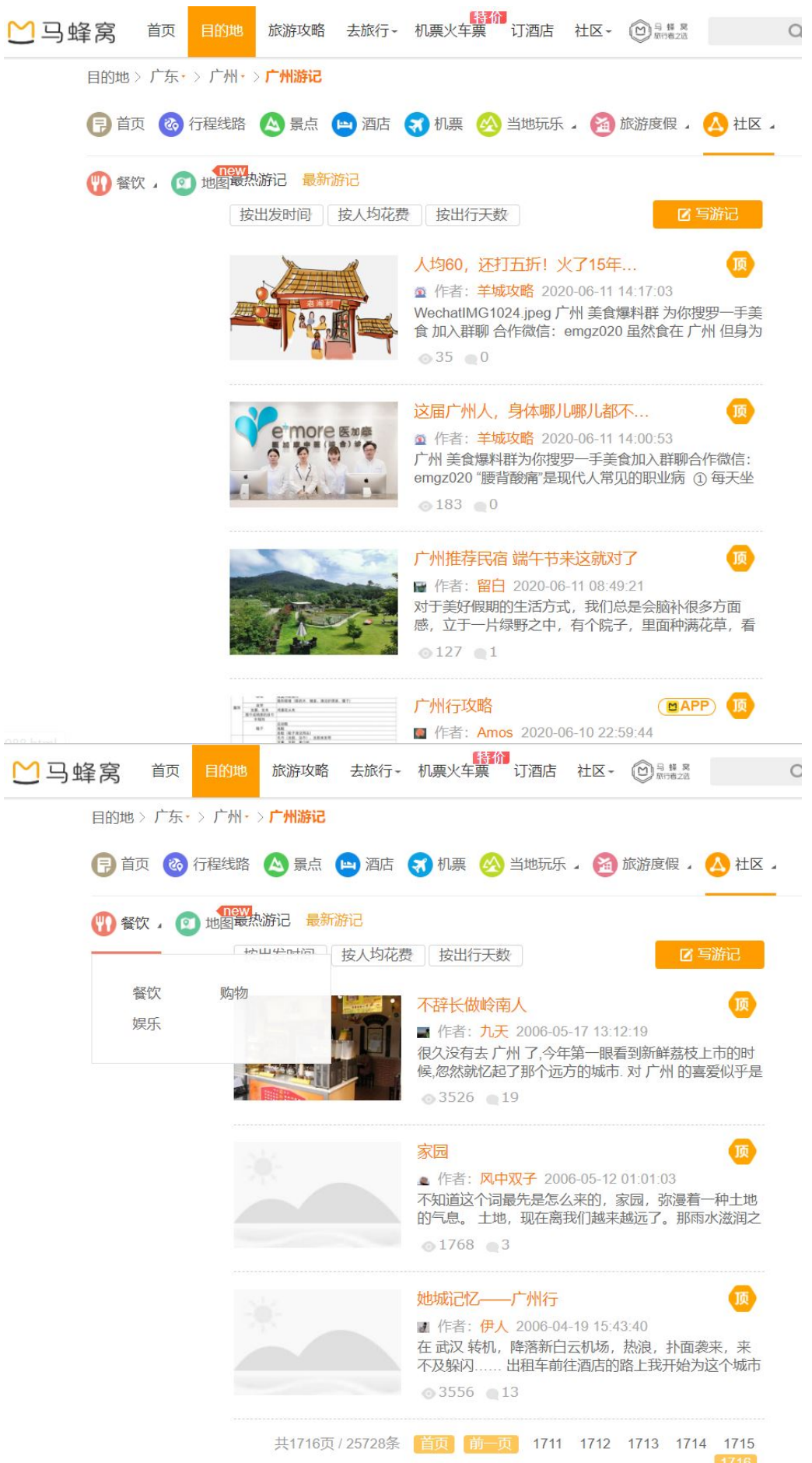

Figure 2. Query page of online travel notes.

title, and replacing them in order of readings from those that were not selected. The final sample totaled 946 articles (see Table 1).

\subsection{Cognitive System and Data Coding}

In the process of data collection, we make a simple identification and description 
Table 1. Overview of data collection.

\begin{tabular}{ccc}
\hline Year & Preliminary Collection/Article & Final Adoption/Article \\
\hline 2010 & 47 & 46 \\
2011 & 136 & 100 \\
2012 & 343 & 100 \\
2013 & 521 & 100 \\
2014 & 301 & 100 \\
2015 & 453 & 100 \\
2016 & 342 & 100 \\
2017 & 488 & 100 \\
2018 & 398 & 100 \\
2019 & 416 & 100 \\
Total & 3445 & 946 \\
\hline
\end{tabular}

of the title content. However, looking back at the previous researches, there is no unified standard for tourism image around the world. Therefore, this paper synthesizes the six elements of tourism and previous researches (Guo et al., 2015; Wang \& Xue, 2019) to reconstruct the indicators of tourism image system as shown in Table 2.

\section{Analysis and Discussion}

\subsection{Perception of Space}

\subsubsection{Geography}

From 2010 to 2019, a total of 22 place names appeared in the title, including 11 city Administrative areas and 11 other cities and regions (see Table 3).

The tourism attraction in Guangzhou is distributed in 12 different Administrative areas, with Nansha District being the most frequently mentioned, followed by Panyu District, Conghua District, Huadu District, Haizhu District and Zengcheng District, while the remaining districts are very less frequently mentioned. Nansha District and Haizhu District have atypical attractors such as wetland parks, which are often tiltled with place names in order to distinguish them. Although Luogang District has one of the "Eight Scenes of Yangtze City", it is located in a remote area with relatively poor tourism resources. Same as Conghua District, Panyu District, Huadu District and Zengcheng District, which are far away from the downtown and their attractions are not familiar to the public, so the attractions name will be titled with where they are located. However, Tianhe District, Yuexiu District, Huangpu District, Liwan District and Baiyun District are adjacent to each other and have convenient traffic access, as well as very well-known tourism attractions, so tourists tend to weaken or omit the districts' names.

Some of the travel notes' titles mention other cities, including 8 cities in Guangdong Province and 2 regions, Hong Kong and Macau. Among them, Zhuhai is most preferred, followed by Shunde District in Foshan, Hong Kong, 
Table 2. System and index of destination image.

\begin{tabular}{|c|c|c|}
\hline Primary Category & Subcategory & Description \\
\hline \multirow[t]{11}{*}{ Words related to geographic names } & Within the city & \\
\hline & Outside the city & $\begin{array}{l}\text { Administrative region where tourism attraction is located in the title of the online } \\
\text { travel notes }\end{array}$ \\
\hline & & The cities around Guangzhou mentioned in the title of the online travel notes \\
\hline & Natural Landscape & $\begin{array}{l}\text { Includes geo-landscapes, waterscapes, biological landscapes, and meteorological and } \\
\text { climatic landscapes }\end{array}$ \\
\hline & Religious Culture & $\begin{array}{l}\text { Includes religious architectural landscapes, religious practice landscapes and } \\
\text { religious art landscapes }\end{array}$ \\
\hline & Historical Monument & $\begin{array}{l}\text { Includes historical and cultural sites of humanity, ancient architecture, ancient } \\
\text { tombs and historical artefacts }\end{array}$ \\
\hline & Folk Customs & $\begin{array}{l}\text { Including food and drink customs, characteristic dwellings, traditional costumes } \\
\text { and handicrafts, marriage and funeral customs, ethnic songs and dances, and } \\
\text { festivals, etc. }\end{array}$ \\
\hline & Literature and Arts & $\begin{array}{l}\text { Including landscape poetry, coupled arts, inscriptions, operas, calligraphies, } \\
\text { paintings, sculptures, etc. }\end{array}$ \\
\hline & & Including characteristic small towns, modern urban scenery and industrial tourism \\
\hline & Town and Industrial & landscape. Modern urban scenery includes urban iconic buildings, modern \\
\hline & Tourism Landscape & $\begin{array}{l}\text { commerce, education, science, culture, sports, health and other activity phenomena } \\
\text { and facilities and urban leisure and entertainment facilities }\end{array}$ \\
\hline Words of destination image & & $\begin{array}{l}\text { Adjectives or descriptors of tourism attractions or destinations mentioned in the } \\
\text { title of travel notes }\end{array}$ \\
\hline Words related to travel emotion & & Adjectives or descriptors of travel experiences mentioned in travel notes \\
\hline \multirow[t]{5}{*}{ Words of travel behavior } & Accommodation & $\begin{array}{l}\text { The specific tourist behaviors, reflecting the tourist's travel style and preferences, } \\
\text { are divided into five categories with reference to the "six elements" of tourism }\end{array}$ \\
\hline & Food & \\
\hline & Transportation & \\
\hline & Shopping & \\
\hline & Experience & \\
\hline Travel duration & & The length of time that tourists spend on their trip \\
\hline
\end{tabular}

Table 3. Frequency of words in relevant destinations.

\begin{tabular}{ccc}
\hline Category & Administrative Area & Frequency (\%) \\
\hline Nansha & 13.67 \\
Panyu & 5.76 \\
Conghua & 5.00 \\
Huadu & 4.32 \\
Haizhu & 4.29 \\
Zengcheng & 4.29 \\
Tnside the City & Tianhe & 2.16 \\
Yuexiu & 2.88 \\
Luogang & 2.86 \\
Huangpu & 2.16 \\
Liwan & 1.43 \\
\hline
\end{tabular}




\begin{tabular}{lcc} 
Continued & & \\
\hline Zhuhai & 39.56 \\
Shunde (Foshan) & 14.29 \\
Hong Kong & 8.79 \\
Shenzhen & 7.69 \\
Macao & 7.69 \\
Futside the City & Foshan & 3.30 \\
& Huizhou & 2.20 \\
Chaoshan & 2.20 \\
Shantou & 2.20 \\
Dongguan & 1.10 \\
Nanao & 1.10 \\
\hline
\end{tabular}

Shenzhen and Macau. In 2014, Zhuhai Changlong opened, and as a famous 5A scenic in Guangzhou, Changlong Resort connects Guangzhou and Zhuhai, diverting some tourists to Zhuhai city. Shunde Districts, ranked second, is known for its delicious food, and close to Panyu and Nansha districts, attracting a large number of tourists who come for the special food culture of "Guangfu". Guangzhou, as the "southern gate", facing Hong Kong, Shenzhen and Macao, and the three cities as the economic pioneer zones, have always been popular destinations for tourists. The accessibility of Guangzhou has formed a peripheral tour route with Guangzhou as the center. The remaining cities and regions were mentioned at less than $4 \%$, suggesting that most travelers with Guangzhou as their core destination are less likely to travel around these cities, possibly due to the relative inconvenience of transportation and the overlap in tourism resources.

The fact that trips including Guangzhou and its surrounding area are more attracted may be due to the weakening and neglect of the geographical names mentioned above on the one hand. On the other hand, the tourism resources in Guangzhou may be homogeneous or barren, and tourists are more inclined to visit different types of destinations to obtain a better comprehensive experience.

\subsubsection{Tourism Duration}

To further explore the distribution and richness of tourism resources in Guangzhou, we extract the travel duration in the title of the online travel notes (see Table 4).

In terms of overall distribution, the words of highest frequency are found to be five days and above, with short-term travel (within and include five days) accounting for 70.43 percent. Among them, the majority of tourists traveling for five days or above across several cities. On the opposite, the duration of the tour inside the city is generally half a day to four days. Tourists of half-day and one-day trip generally choose 1 - 2 small attraction, such as "Dongchong western style houses trip", "Dongshan Yanglou, Xiguan Arcade half day trip”. Very few 
Table 4. Frequency of words in days of travel.

\begin{tabular}{ccc}
\hline Duration & Frequency (\%) & Description \\
\hline $\begin{array}{c}\text { Five days and above } \\
\text { One-day trip }\end{array}$ & 22.67 & Long-term holiday including the National Holiday \\
Three-day trip & 19.18 & $\begin{array}{r}\text { Including holidays such as Qingming and Dragon Boat } \\
\text { Festival, which are generally three days in length }\end{array}$ \\
Two-day trip & 13.38 & Including a weekend trip \\
Tour-day trip & 12.79 & \\
Half-day trip & 2.99 & \\
\hline
\end{tabular}

tourists choose intensive tour mode, quickly visiting the classic attraction, such as "Guangzhou line day trip (Sacred Heart Cathedral - Zhongshan Memorial Hall - Yuexiu Park - Shangxiajiu - Shamian - Red Factory - Guangzhou Tower)". Tourists who traveled for 2 - 4 days tend not to mention the attraction of the visit, but to use generalized language to describe it, such as "Happily Eating and Drinking on New Year's Day in Guangzhou for 4-Day", "Guangzhou Food Tour for 3 days". Some tourists chose to focus on a particular tourist attraction, especially the characteristic town and resort area, such as "Guangzhou Changlong Wildlife World Trip during the Dragon Boat Festival”.

As is shown in Figure 3, in terms of annual variation, the frequency of longer trips increased after 2013 and even exceeded half of the total amount in 2019, possibly due to:

1) Increased economic level and sufficient personal capital for travel.

2) Increased awareness of leisure and people's willingness to spend more time on the trip.

3) New attractions are built and people need to spend more time travelling around.

4) Radiation Effect of Policies such as Guangdong-Hong Kong-Macao Greater Bay Area, bringing passengers to the surrounding cities outside Guangzhou, people are more inclined to travel around more cities in one trip.

However, the short length of duration is still predominant and the proportion of peripheral travel has increased, indicating that.

1) Most travelers prefer to visit the classic attractions, which are relatively concentrated and people don't need to spend much time on.

2) Guangzhou is well developed in its transportation, which reduces travel time for tourists.

3) There are still few tourism resources that are well known or of interest to tourists, and tourists do not need to spend more time on them.

4) Travelers have less time for leisure and most travel during short holiday.

\subsubsection{Tourism Attraction}

With reference to the statistics of the annual changes, "religious and cultural" accounts for the lowest proportion, and occasionally missing from the figure; 


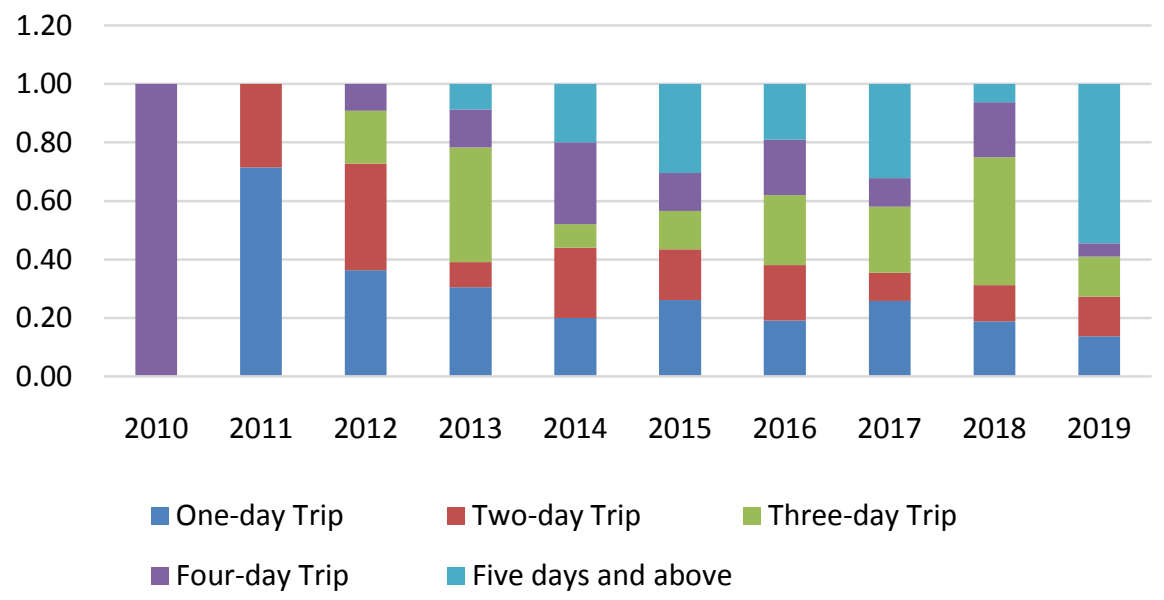

Figure 3. Changes in duration of travel.

followed by "folklore and customs". "Natural landscape" maintains a relatively stable changes in a low attractiveness for these years. "Historical monuments" changes steadily with a huge attractiveness, perennial ranking the third. "Literature and art" appears very frequently, and the attractiveness generally ranks second, with ranking first in 2011. "Towns and industrial tourism" generally ranks first, far beyond other types of resources (see Figure 4).

As the earliest city opening to the outside world, Guangzhou possesses a great amount of religious and cultural sites, such as the Sacred Heart of Ishiguro Cathedral and the Six Banyan Temple. Due to its off-shore geographical location, it also gave rise to local religions such as the Tian Hou Gong. However, compared to other attractions, religious culture is more ornamental on account of the artistic value of its architecture, and its recreational value is relatively low. Hence, its attractions are of low attractiveness.

Guangzhou is rich in its special cultural, but people are mostly familiar with the architectural culture such as arcades and Cantonese cuisine culture. Cultures such as Cantonese opera, embroidery and other traditions are not popular and only have a small group of audiences. Lion dance and other cultural performances as well as folk festivals are often shown in certain celebration activities, which are of regionalism and timeliness, so attractions of folk culture that are popular to tourists are limited to fixed places, such as the arcades in Shangxiajiu Street, sculpture of Chen Clan Academy and exhibition in Baomo Garden, etc. Meanwhile, this kind of attraction has a certain homogeneity, although folk culture is scattered in different places, but its essence and connotation have high similarity, so tourists travel selectively and which results in a low attractiveness.

Located in the subtropics, Guangzhou is surrounded by year-round greenery and has a number of forest parks and scenic resorts, including timeless ecological landscapes in historical monuments, so there is a wide range of places to visit. At the same time, Guangzhou has the name of "Flower City"; some parks have famous scenery or enjoyable events, such as the beautiful view of plum in Xiangxue Park and bungee jumping event in Baiyun Mountain, which attracts 


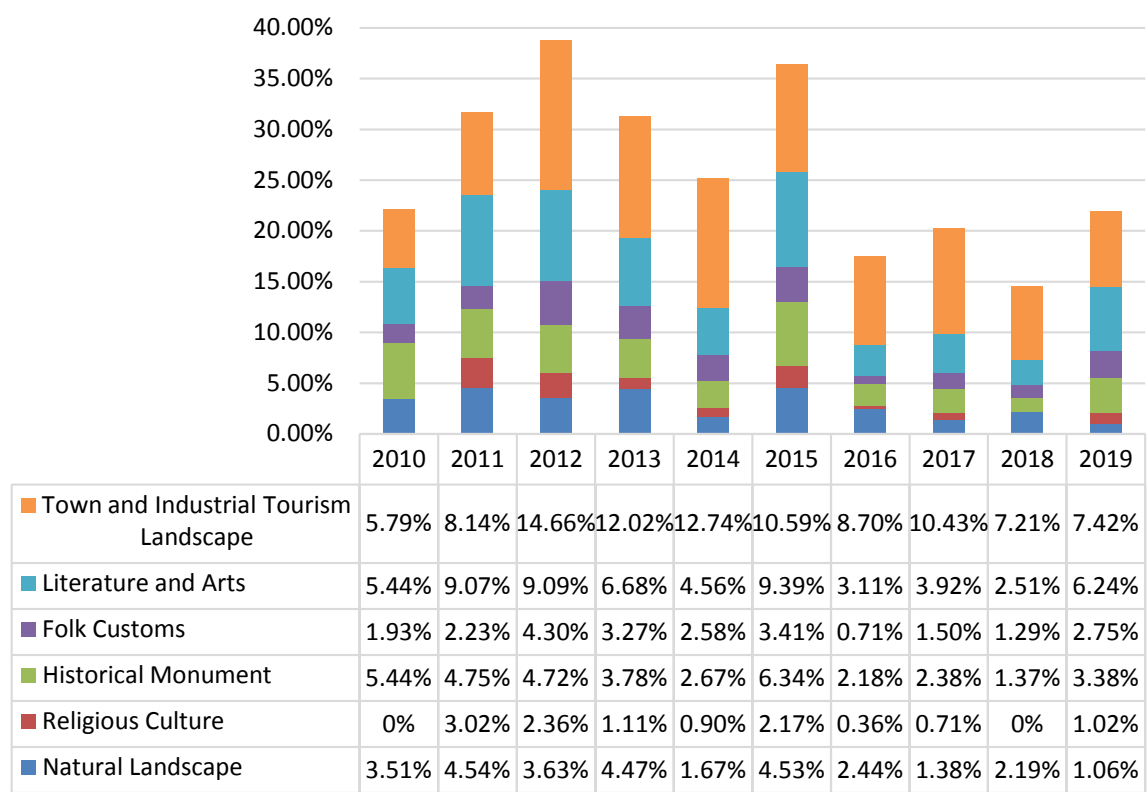

Figure 4. Changes in visits of attractions.

many tourists every year. The attractiveness of this category of resources has therefore been relatively high.

Literature and art, as a highly integrated tourism resource, is often attached to other tourism attractions, with a strong clustering between folk customs, historical monuments, and also often with religious culture (see Figure 5). With the development of modern culture and the continuous enrichment of people's awareness of culture, art museums, art exhibitions and other independent literature and art attractions continue to emerge, such attractions can be subsumed under the category of "towns and industrial tourism landscape", thus showing a very high degree of attractiveness and frequency of appearance, even with the strength to be compared with the urban landscape.

Urban and industrial tourism landscape has been the main tourist resources of modern cities. Characteristic towns, resorts (such as the European town of Jiulong Lake in Huadu), Changlong Resort, and especially Changlong Resort, as the most popular characteristic resort, combined with major variety TV shows, attracts millions of tourists every year. As a representative of classical "Guangfu" culture and historical feature, modern commercial pedestrian streets, such as Shangxiajiu and Beijing Road, have always been popular attractions. While cultural and creative industrial parks such as Hongzhuan Factory, Kuiyuan and $\mathrm{Zi}$ Ni Tang, which have been rebuilt in recent years, have also become more and more popular among tourists, becoming mecca for tourists to take photos and post on the social media. Since the 2010 Guangzhou Asian Games, a number of new landmarks of Guangzhou, such as the Guangzhou Tower, Haixinsha and a series of "Guangzhou New Eight Scenes" have become the symbols of Guangzhou with their modern urban characteristics, as well as the "must-see" tourist attractions. In addition, educational resources such as Sun Yat-sen University 


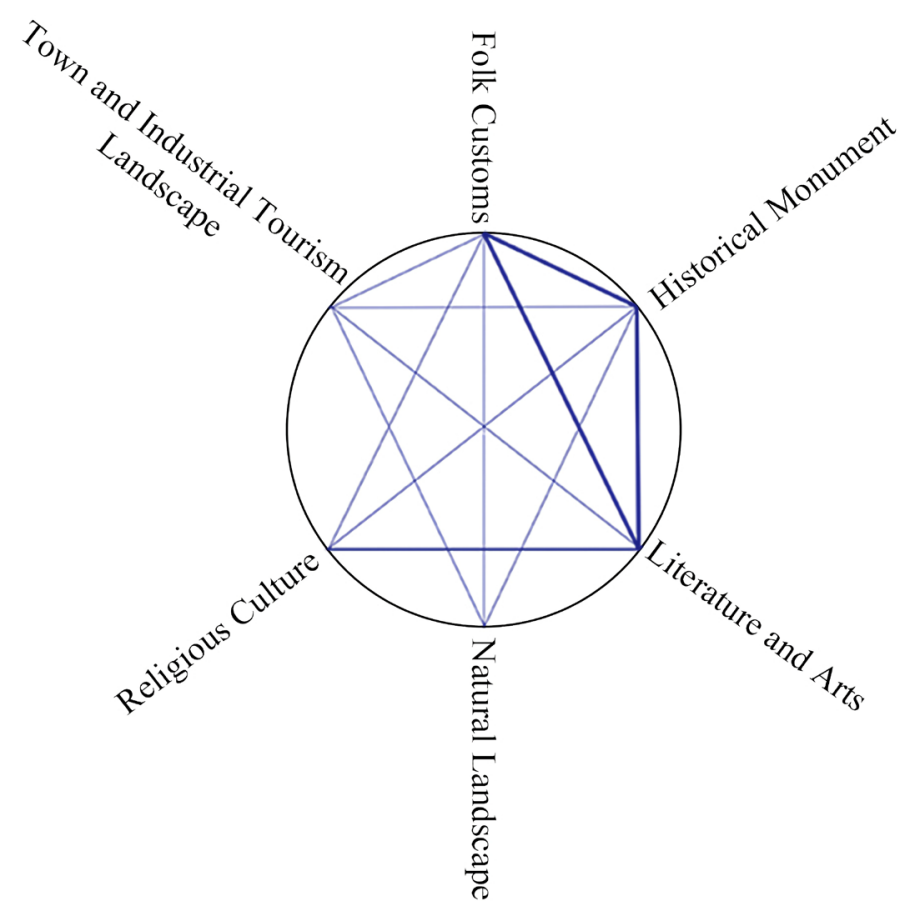

Figure 5. Cluster analysis of attractions.

and South China University of Technology are also open to the public, and some universities have highly valuable natural landscapes and unique architectural styles, especially the "flowering cherry viewing" of South China Agricultural University and the architecture of the republic period in Sun Yat-sen University. These are also one of the attractions for tourists. As a result, the towns and industrial tourism landscape is always at the top of the attraction list due to its strong relevance, large resource capacity and rapid renewal.

\subsection{Emotion}

For the emotion perception of tourism attraction, by combining similar adjectives, such as "unexpected", "unknown" and other words to categorize "niche", and come up with the following high-frequency words. In general, tourists' perception of Guangzhou city image is mainly positive. By summarizing, the image of Guangzhou city can be divided into the following categories: leisure experience, such as "leisure", "fun", "fresh", "romantic", "wonderful", "paradise", accounting for 7.49\%; history and culture, such as "history", "literature and art", "combination of Chinese and Western", "exotic", accounting for 6.66\%; local food and customs, such as "delicious", "old Guangzhou", accounting for $4.3 \%$; natural ecology, such as "flower city", "nature", "nimbus", "beautiful”, accounting for $3.51 \%$; modern city, such as "prosperous", "gorgeous", "fashion”, "marketplace", accounting for $3.49 \%$. In particular, Guangzhou, with its unique culture and history, has established a proprietary image to its tourists described as "Old Guangzhou” (see Table 5). Therefore, we can conclude that tourists' perception of Guangzhou city image is mainly formed by leisure experience, followed by 
Table 5. Frequency of words in emotion.

\begin{tabular}{cccc}
\hline Characteristics & Frequency (\%) & Characteristics & Frequency (\%) \\
\hline Literature and Art & 3.65 & Nature & 0.68 \\
History & 2.51 & Fashion & 0.67 \\
Old Guangzhou & 2.48 & Niche & 0.67 \\
Leisure & 2.35 & Marketplace & 0.5 \\
Delicious & 1.82 & Combination of Chinese and Western & 0.33 \\
Paradise & 1.66 & Wonderful & 0.33 \\
Flower City & 1.65 & Exotic & 0.17 \\
Prosperous & 1.49 & Yangquan Restaurant & 0.17 \\
Fun & 1.33 & Gulangyu Island & 0.17 \\
Beautiful & 1.01 & Unique & 0.17 \\
Romantic & 0.99 & Mysterious & 0.17 \\
Fresh & 0.83 & Nimbus & 0.17 \\
Gorgeous & 0.83 & Zhouzhuang & 0.17 \\
\hline
\end{tabular}

history and culture, local food and customs, natural ecology, and modern city is ranked last, indicating that tourists visit Guangzhou more for its cultural heritage than for modern construction. In addition, it is worth mentioning analogies such as "Zhouzhuang", "Gulangyu" and "Yangquan Restaurant", famous scenic in other cities indicating that tourists will compare the similar attractions in different destinations, or use similar attractions in other well-known destinations as a yardstick of evaluation.

\subsection{Behavior}

As can be seen from Figure 6, food and experience are the main elements in the titles of online travel notes, followed by accommodation and transportation, with shopping being the least mentioned, indicating that the traveler attaches great importance to the mode of travel and local typical food. Shopping is integrated into the entire travel and the shopping place is not usually the main attraction, so it does not often appear in the titles; transportation and accommodation are the same, however, when there are innovative facilities and activities included about these elements in the trip, people are more willing to mark in the titles.

In the category of "transport", Trekking is the first with 20.66 percent, followed by public transport. Trekking is a common way when visiting natural scenic, combining the above attractiveness analysis of natural landscapes, traveling to forest parks on foot is more attractive to tourists. Besides, it shows that Guangzhou is convenient for public transport and offers a variety of options for tourists to travel.

In the category of "Food", words of high frequency are "food", "eating and 


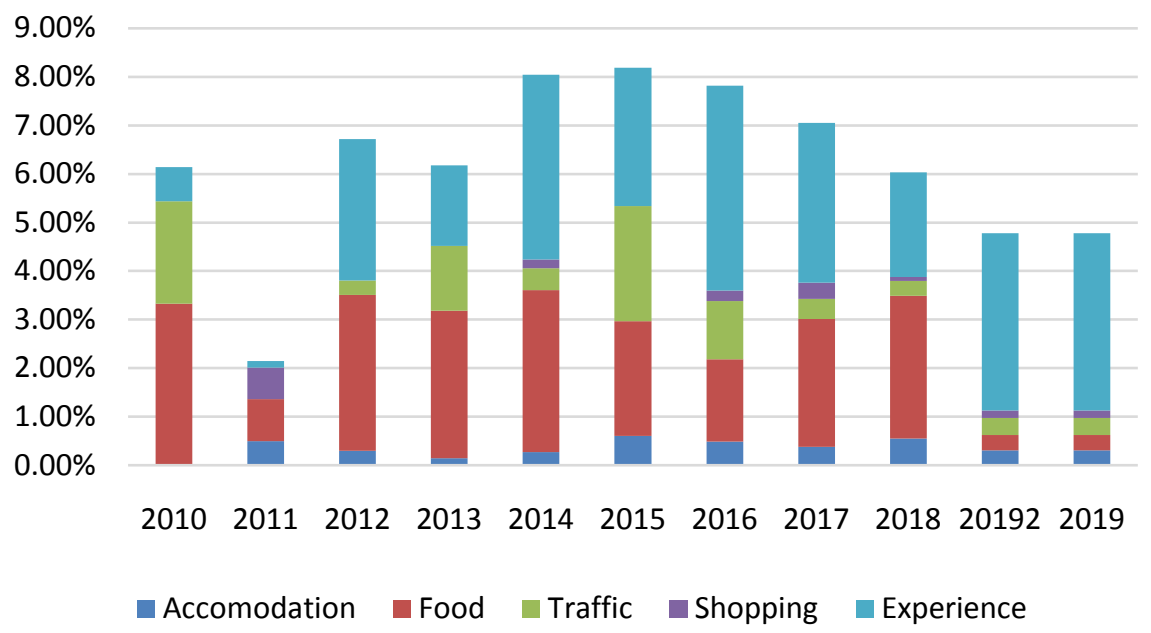

Figure 6. Changes of dimensions in action.

drinking", "seeking for delicacy" and "tip of the tongue", which are all generalized terms, indicating that Guangzhou's food resources are quite rich and tourists tend to have a holistic experience. Words such as "morning tea", "seafood", " syrup " and "snacks" indicate the characteristics of Guangzhou's "morning tea" culture and the off-shore geographical location. Finally, "traditional brand", although not frequent, indicates the long history of Guangzhou food culture.

In the category of "shopping", specific words such as "bookstore", "shopping mall", "home", "pedestrian street", "flower market", appear in high frequency, indicating that tourists are concerned about specific shopping facilities. Among these words, "flower market" as part of the Guangzhou Spring Festival culture, attracts those tourists who travel during the Spring Festival. Therefore, it can be promoted as an outstanding festive characteristics of Guangzhou Spring Festival culture.

In the category of "accommodation", "hotel" appears the most often, indicating that most travelers still choose hotels as their accommodation when traveling. "Sofa" belongs to the youth hostel accommodation, generally chosen by "budget travel" lovers. But because it is not that comfortable and insecure, so its audience group is small. With the rise of minshuku, the term "minshuku" should also be attached great importance, but it is not mentioned frequently.

In the category of "experience", travel as "family" appears most frequently, indicating that Guangzhou is a city suitable for every age. At the same time, a series of leisure experience words, such as "spring country walk", "blowing", "seaside", "vacation", "fishing" and other leisure experience correspond to the greatest preference in leisure experience mentioned in emotion perception (see Table 6).

\section{Conclusion and Discussion}

\subsection{Conclusion}

The destination image extracted from the online travel notes is the composite 
Table 6. Frequency of words in experience.

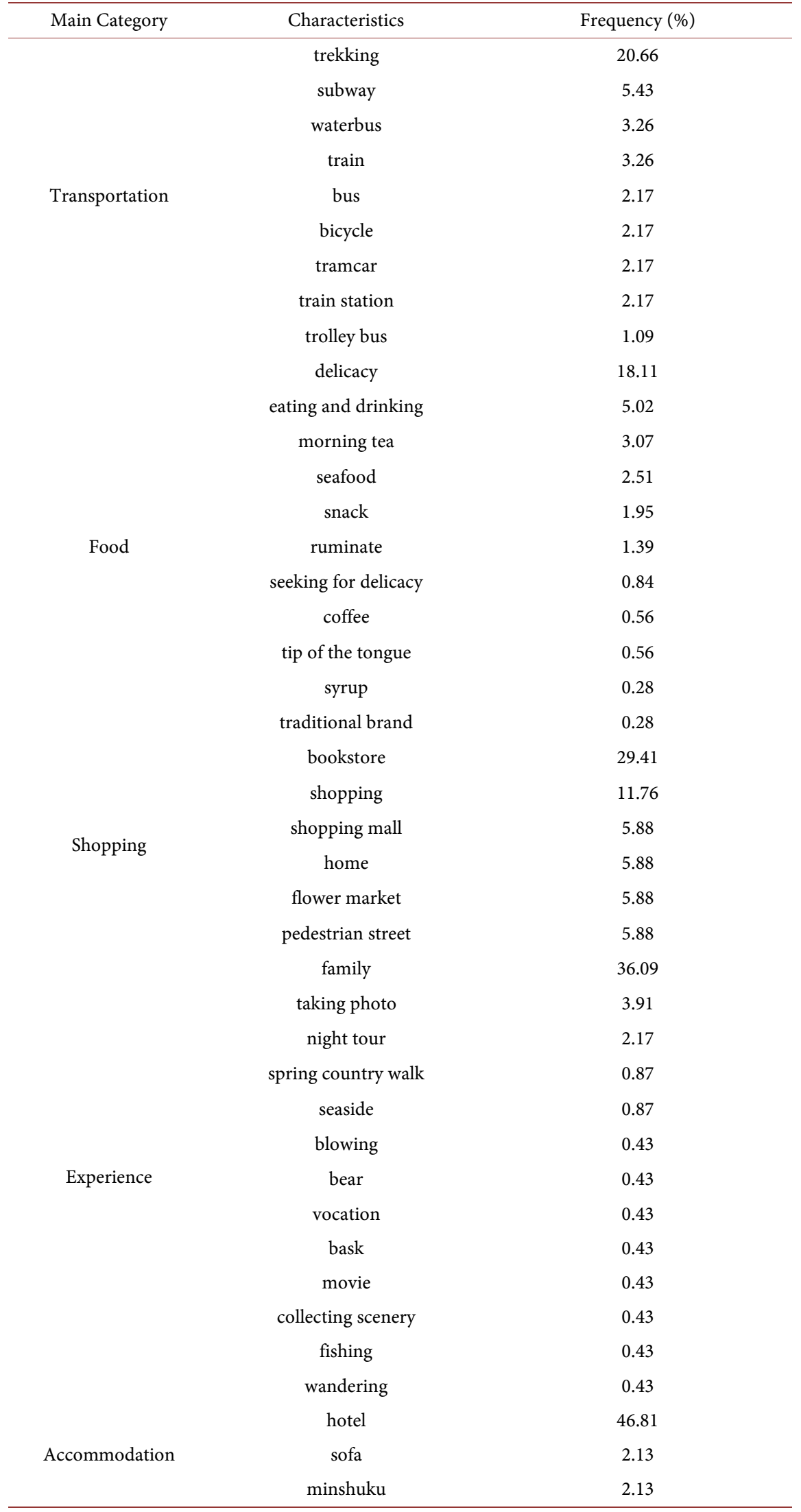


image formed after the tourists' actual travel, that is, the composite image perception is the native image perception of the potential tourists. Meanwhile, the tour title is sorted according to the amount of reading and the recommendation, so the potential tourists will selectively form their perception according to their own interests. Through the analysis of travel notes, we can find out the factors that tourists value and thus help DMOs carry out more targeted marketing publicity.

By sorting out the titles, we analyze and study the change of the native image of Guangzhou city based on three levels: space, emotion and behavior, and therefore draw the following conclusions:

First, from the point of view of spatial perception, the city tourism attraction is enormous, but distributed in different administrative areas, which makes tourists difficult to plan their trips. Also, the homogenization of similar tourism resources results in the relatively barren situation of tourism resources. Besides, the time that tourists have spent in Guangzhou City is short, but more in the surrounding cities, so DMOs should pay more attention to the loss of tourists.

Second, from the point of view of emotional perception, Guangzhou is a leisure-oriented city that people can "slow down". Tourists have a full sense of its historical and local characteristics, which makes the image characteristics of "Guangfu" culture highlighted. However, the urban image perception is not that strong, so we need to strengthen the promotion of its modernization, in order to better integrate its lingering charm and prosperity.

Third, from the perspective of behavior perception, Guangzhou's food culture and parent-child travel projects can be the focuses of propaganda. At the same time, DMOs should pay attention to the construction of shopping, transportation and accommodation, such as building more theme hotels, IP joint subway cars, creative concept store and other attractive tourism resources.

\subsection{Suggestions}

\subsubsection{Increase Tourism Resources}

The relative stability of Guangzhou tourism reflects the lack of tourism resources in Guangzhou, so tourists are limited to some fixed destinations, such as Shamian Island, Shangxiajiu streets, Beijing Road and so on. Therefore, we put forward two suggestions: introducing new technology to the old scenic and integrating new attractions with local characteristics. The old tourism resources have accumulated a high popularity, so the government and related enterprises can use 5G, VR, AI and other high-tech to bring new experience to travelers. Due to its long history, some attractions in Guangzhou lack a sense of interactivity in order to protect the places' facilities and therefore focus on only sightseeing. Hence, VR and AR technology can be incorporated to make visitors feel as if they are in the historical screen and interact with the museum's furnishings to enhance interactivity. As for the construction of new tourism resources, they can start with the trend culture, refer to the upsurge of idea stores, relying on Guangzhou's rich university resources, and make full use of the school's artistic 
talent resources. However, at the same time of new construction, we should consider its integration with urban culture. The tag of "historic city" should not be discarded. How to dig out the cultural heritage of "old Guangzhou" should be attached great importance on. In addition, the relevant marketing organizations should pay attention to means of propaganda at the age of new media, flexibly operate the official weibo, Wechat official accounts platform, and use more UGC to build up the official image, so that tourists can realize the high status of their own voice, in order to encourage tourists to actively create more positive propaganda content.

\subsubsection{Appropriate Guidance on UGC Creation}

The urban image is unchanged throughout the time. On the one hand, it is the result of the lack of tourism resources; on the other hand, it is the effect of the "agenda setting" theory. "Agenda Setting" is the basic theory in communication, which refers to the media's ability to control what topics the public should be discussing. Transferring to the influence by UGC on potential tourists, it can be considered that UGC, a kind of "media", has the ability to guide tourists to pay attention to certain tourism resources, and their travel plan, which leads to different tourists repeatedly to the same destination. DMOs still to serve as a guide for tourists, and the official accounts can direct UGC production on social media platforms to like, comment and forward by focusing on experiences sharing on emerging tourism resources, introducing new ways to explore the classical scenic, and so on. According to Yang and Jiang (2020), the motivation of creating UGC includes the commercialized of "we media", so the official can cooperate with the commercial "we media" by offering travel sponsors in order to guide their writing. Meanwhile, as "audiences" change to "users" at the era of web2.0, readers of travel notes become more proficient in mastering the initiative. So in the process of guidance, DMOs need to respect the will of readers, give more space to travelers in creation and reducer obvious blunt advertisement in propaganda.

\subsection{Research Contributions}

In the age of information inflation, people increasingly prefer fragmented and short information. When sifting through the information and making travel plans, people decide whether to read further based on the attractiveness of the titles of the online travel notes, thus the title can reflect people's travel preferences to some extent. Most existing studies start from the full text of the travelogue to conduct an in-depth analysis of tourists' preferences, and textual studies are close to saturation. Besides, as images, Video and other forms of media become more and more popular, the analysis of text seems to have fallen out of favor, but text is still the main form of travel notes, and the competition of attracting more readers is more intense. Therefore, this paper hopes to provide a fresher perspective for future analysis of online travel notes, and to suggest ways to attract visitors quickly and effectively. 
Secondly, Guangzhou, as one of the core cities in the Guangdong-Hong Kong-Macao Greater Bay Area, is responsible for supporting the development of neighboring cities as well as being a tourist destination of the old guard. Therefore, how to maintain its own tourism status based on supporting the development of neighboring cities and how to enhance its attractiveness to help develop its economy are the practical meanings that the paper desires to achieve.

\subsection{Research Defects and Prospects}

Nowadays, online travel notes play an important role in making travel plans. The destination marketing organization needs to focus on how tourists filter and choose travel notes, so as to use the east wind of the mass communication and get close to tourists, maintain and improve the attractiveness of the destination.

This paper is to help explore the change in image of Guangzhou city, but there are still some shortcomings. First, the sample is only collected in one single tourism website, so in the future more large social media platform such as weibo, should be considered. Second, the sample content is limited, because a vague title is much easier to attract people to read, and the platform's recommendation algorithm promotes more about advertisements. So in order to ensure the standard set for reading and recommendation, our sample size is small; finally, on account of the limitation in technology, the subjectivity of manual judgement is hard to overcome. We can try to improve the accuracy in coding with big data training and deep learning skills.

\section{Acknowledgements}

This paper is supported by the Guangdong Provincial Science and Technology Plan Project (Grant No. 2018A070712022).

\section{Conflicts of Interest}

The authors declare no conflicts of interest regarding the publication of this paper.

\section{References}

Alhemoud, A. M., \& Armstrong, E. G. (1996). Image of Tourism Attractions in Kuwait. Journal of Travel Research, 34, 76-80. https://doi.org/10.1177/004728759603400413

Álvarez, H. R., Fierro, C. J. J., \& Blasco, F. M. (2020). The Interplay between Social Media Communication, Brand Equity and Brand Engagement in Tourist Destinations: An Analysis in an Emerging Economy. Journal of Destination Marketing \& Management, 16, Article ID: 100413. https://doi.org/10.1016/j.jdmm.2020.100413

Baloglu, S., \& Brinberg, D. (1997). Affective Images of Tourism Destinations. Journal of Travel Research, 35, 11-15. https://doi.org/10.1177/004728759703500402

Cai, X. M., \& Lai, Z. J. (2007). Empirical Research on Visitors of Image Perception for the Landscape of Food Culture in Guangzhou. Human Geography, No. 1, 63-66.

Dai, G. Q., \& Chen, X. (2010). The Visual Representation Analysis of Shangxiajiu Street in Guangzhou City. Human Geography, 25, 148-153+91. 
Deng, M. Y. (2002). Exploration of Emeishan Tourism Destination Image Positioning. Journal of Southwest University for Nationalities, No. 4, 177-179.

Deng, N., Liu, Y. F., Niu, Y., \& Ji, W. X. (2019). Different Perceptions of Beijing's Destination Images from Tourists: An Analysis of Flickr Photos Based on Deep Learning Method. Resources Science, 41, 416-429.

Enright, J. M., \& Newton, J. (2004). Tourism Destination Competitiveness: A Quantitative Approach. Tourism Management, 25, 777-788. https://doi.org/10.1016/j.tourman.2004.06.008

Fakeye, P. C., \& Crompton, J. L. (1991). Image Differences between Prospective, First-Time, and Repeat Visitors to the Lower Rio Grande Valley. Journal of Travel Research, 30, 10-16. https://doi.org/10.1177/004728759103000202

Feng, J. Y. (2011). Perceptions of the Image of Beijing's Tourist Destinations-An Analysis of the Multi-Dimensional Discourses on the Blogs from Chinese and Western Tourists. Tourism Tribune, 26, 19-28.

Feng, J. Y., \& Huangpu, J. K. (2017). New Media Research on the Tourism Image of the Forbidden City-Discourse Analysis Based on TripAdvisor Online Travel Notes. Modern Communication (Journal of Communication University of China, 39, 137-143.

Gallarza, G. M., \& Saura, G. I., \& Garcí, H. C. (2002). Destination Image: Towards a Conceptual Framework. Annals of Tourism Research, 29, 56-78. https://doi.org/10.1016/S0160-7383(01)00031-7

Guo, F. H., Wang, K., Zhang, J. L., \& Li, R. J. (2015). Rural Tourism Destination Image of the Case in "Five Golden Flower", Chengdu: Based on the Text Mining of Blogs. Tourism Tribune, 30, 84-94.

Guo, J. J. (2012). Research on the Construction of Tourist Destination Image Based on the Government Tourism Web Site-A Case Study of Zhouzhuang. Quanhou: Huaqiao University.

Guo, Q. G. (2011). Journalism and Communication (2nd ed.). Beijing: China Renmin University Press.

Guo, Y. Z. (2003). Summarize on the Study Results of Tourism Apperceiving Image. Economic Geography, No. 2, 280-284.

Huang, P., Xia, Y. H., \& Li, X. H. (2020). Temporal and Spatial Characteristics of Landscape Imagery of Yunshuiyao Ancient Town Based on UGC Data. Journal of Chinese Urban Forestry, 36, 17-21.

Huang, Y. H. (2014). A Study of Tourists' Social Network Behaviors from a Postmodern Perspective. Tourism Tribune, 29, 9-11.

Jiao, Y. H., \& Fang, W. Q. (2010). Beijing Road Pedestrian Street of Guangzhou: Representation of the Social Transformation in China. Urban Planning International, 25, 62-66.

Liang, J. Y. (2018). Evolution of Tourism Nodes and Paths in Guangzhou's Old City Based on Online Travel Notes. In Proceedings of 2018 China Urban Planning Annual Conference (05 Urban Planning New Technology Application) (pp. 1175-1185). Hangzhou: China Architecture \& Building Press.

Liao, W. H. (2007). Research on the System of Tourism Destination Image and Tourists' Cognitive Differences: A Case Study on Guangzhou. Journal of Jinan University (Philosophy and Social Sciences), No. 2, 59-64.

Liu, B. K. (2014). Research on the Communication of Urban Image in the Beijing-Hangzhou Grand Canal Basin. Modern Communication (Journal of Communication University of China), 36, 17-21. 
Liu, D. P. (2007). Tourist Gaze: From Foucault to Urry. Tourism Tribune, No. 6, 91-95.

Liu, J. F., Wang, G. Y., \& Zheng, B. (2009). Study of Constructing Tourist Destination Image. Tourism Forum, 2, 479-484.

Liu, Y. M. (2019). Study on the Image of Shenyanng's Urban Tourist Destinations: Communication Analysis Based on UGC Travel. Shenyang: Liaoning University.

Lu, L. J., \& Liao, X. P. (2019). Research on Image Perception of Tourism Destination Based on UGC Data: A Case Study of South Mount Heng. Economic Geography, 39, 221-229.

Pi, R. (2018). A Comparative Study on the Visual Representation of Destination Tourism Image Based on Marketing Pictures and Tourist Photographs. Zhengzhou: Zhengzhou University.

Pike, S. (2002). Destination Image Analysis-A Review of 142 Papers from 1973 to 2000. Tourism Management, 23, 541-549. https://doi.org/10.1016/S0261-5177(02)00005-5

Qu, H., \& Liang, Y. K. (2017). Web-Based Research on Image Perception of Tourism Destinations in Guangzhou. Social Sciences in Guangdong, No. 6, 202-209.

Shin, S., Chung, N., Zheng, X., \& Koo, C. (2019). Assessing the Impact of Textual Content Concreteness on Helpfulness in Online Travel Reviews. Journal of Travel Research, 58, 579-593. https://doi.org/10.1177/0047287518768456

Stepchenkova, S., \& Zhan, F. (2013). Visual Destination Images of Peru: Comparative Content Analysis of DMO and User-Generated Photography. Tourism Management, 36, 590-601. https://doi.org/10.1016/j.tourman.2012.08.006

Urry, J. (1992). The Tourist Gaze and the "Environment". Theory, Culture \& Society, 9, 1-26. https://doi.org/10.1177/026327692009003001

Wang, D., Chan, H., \& Pan, S. (2015). The Impacts of Mass Media on Organic Destination Image: A Case Study of Singapore. Asia Pacific Journal of Tourism Research, 20, 860-874. https://doi.org/10.1080/10941665.2014.948464

Wang, K., Guo, F. H., Li, R. J., \& Fu, X. Q. (2014). Tourism Attention Degree about China from Overseas and Its Spatial Patterns Based on Tripadvisor. Progress in Geography, 33, $1462-1473$.

Wang, Z. Q., \& Xue, J. H. (2019). Interpretation of Tourism Destination Image Symbols Based on Network Text Analysis: A Case Study of Gulangyu Island in Xiamen. Journal of Neijiang Normal University, 34, 81-87.

Wu, M. Y., \& Shen, H. L. (2018). A Study of the Relationship between Visual Materials and Destination Image in the New Media Era. Tourism Tribune, 33, 5-7.

Xie, C. W., \& Huang, Y. S. (2002). A Research on the Organizational Model of Planning Destination Image Based on Social Participation. Tourism Tribune, No. 2, 63-67.

Yan, Y. Y., \& Zheng, Q. M. (2020). Research on Tourism Image Perception of Great Wall National Park-Based on Content Analysis and IPA. Forestry Economics, 42, 44-50.

Yang, S., \& Jiang, X. L. (2020). An Investigation of the Pattern and Evolution of UGC Production Motivation from the Perspective of Self-Determination Theory. Modern Communication (Journal of Communication University of China), 42, 35-40.

Zang, D. X., \& Huang, J. (2007). A Review of Overseas Studies on Destination Image: Based on the Articles of Tourism Management and Annals of Tourism Research in the Last Decade. Tourism Science, No. 6, 12-19.

Zhao, M. X., Xu, G. F., \& Li, R. R. (2015). The Pictorial Expression of City Image on Internet: A Case Study of Twenty One Cities in Guangdong. Architectural Journal, No. 2, 44-49.

Zhu, Q. J., \& Lu, L. (2016). Evaluation of City Image Elements of Guangzhou under the 
Perspective of Business Exhibition Travelers. Tourism Forum, 9, 8-13.

Zhu, Y., Zhou, Y. G., \& Chen, L. (2019). Analysis of Spatial Characteristics of Urban Tourism Flow Based on UGC Data-Taking Shanghai as an Example. Tourism Forum, $12,33-41$. 